\title{
HIV Exposed Infants Feeding Practices and Associated Factors Among Mothers Attending PMTCT Clinics at Ambo Town Public Health Facilities
}

\author{
Kefyalew Taye Belete \\ Department of Public Health, College of Medicine and Health Science, Ambo University, Ambo, Ethiopia
}

Email address:

kefyalewtaye24@gmail.com

To cite this article:

Kefyalew Taye Belete. HIV Exposed Infants Feeding Practices and Associated Factors Among Mothers Attending PMTCT Clinics at Ambo Town Public Health Facilities. Journal of Health and Environmental Research. Vol. 6, No. 2, 2020, pp. 31-36.

doi: $10.11648 /$ j.jher.20200602.11

Received: September 9, 2019; Accepted: November 6, 2019; Published: April 29, 2020

\begin{abstract}
About thirty seven million people worldwide were living with human immunodeficiency virus in the year 2017, of these, 1.8 million were children ( $<15$ years old). Most of these children live in sub-Saharan Africa and were infected by their human immunodeficiency virus from positive mothers during pregnancy, childbirth or breastfeeding. The study aimed to assess human immune deficiency virus exposed infants feeding practices and associated factors among mothers on prevention of mother to child transmission clinics at Ambo town public health institution. Facility based cross-sectional study was conducted from May to August 2019, at Ambo town public health institution. Systematic random sampling method was utilized to select study respondents. Data were collected through an exit interview by using pre-tested structured questionnaire. The returned questionnaires were checked for completeness, cleaned manually and entered to epidata version 3.1 and then exported SPSS version 20.0 for further analysis. Univariate and multivariate logistic regression analyses were carried out and finally descriptive finding was presented using frequency distribution tables and graphs. From total of 106 respondents $44(42 \%)$ were greater than or equal to 30 years old and majority $(75.5 \%)$ were from urban and more than half $(56.8 \%)$ had good knowledge towards infant feeding practice. About $53.8 \%$ of the children were exclusively breast fed, whereas $28.3 \%$ ) and $17.9 \%$ had practiced mixed feeding and exclusive replacement feeding respectively. This study result identified that the main reason reported for Exclusive Breast Feeding were advised by health professionals, easily availability of breast milk and nutritional importance among the study population. Thus Health professionals working at prevention of mother to child transmission clinic should work on infant feeding practice options by using mass media, community mobilization and health education in more comprehensive.
\end{abstract}

Keywords: Ambo Ethiopia, HIV-positive Mothers, Infant Feeding Practice

\section{Introduction}

Worldwide about 36.9 million people were living with HIV/AIDS by the year 2017. Out of this about 1.8 million people were children aged less than fifteen years and leaving in sub-Saharan Africa. Most of the children were infected with the virus during pregnancy, delivery and breast feeding $[1,2,3]$. Similarly Ethiopia, one of the poorest country in the Horn of Africa, carries the highest burden of HIV/AIDS with prevalence of $1.1 \%$ among Adults aged 15-45 years and 3.4\% among children aged less than five years, where child to mother transmission was the main route of acquisition of the virus [4, 5]. Literatures show that HIV transmission pace is approximated to be 5-10\% during antenatal, $10-15 \%$ during labor and child birth, and 5-20\% after birth during breast feeding. Meanwhile the risk of HIV transmission increases as duration of breast feeding increases [2,6]. However breast milk provides sufficient nutrient requirements of the infant. Thus prioritization of risk benefit analysis is very crucial to prevent HIV transmission while breast feeding [7].

To prevent Non-HIV related morbidity and mortality of infants WHO recommends exclusively breast feeding for the first six months and continue to breastfeed for at least 12 months while introducing complementary foods. World Health Organization recommends Exclusive breast feeding, in areas where exclusive replacement feeding was not 
feasible, acceptable and safe [6]. The current WHO update recommends mothers living with HIV must breastfeed for at least twelve months and could continue breastfeeding for up to 24 months or beyond given they are receiving ART [11]. In the first six months of age exclusive replacement feeding should not be used unless safe and sufficient formula feeds are accessible [8-11].

Infants those who born from HIV positive mothers were more likely to be infected, unless preventative measures are strictly taken [13]. In Ethiopia breast feeding is custom. Nevertheless, only 58\%children are exclusively breast fed and $76 \%$ continue breast feeding for two years and above. Where $74 \%$ of women know that HIV can be transmitted through breastfeeding of whom, only 48 percent of women know that the risk of mother to child transmission can be reduced by taking special drugs [12]. This indicates the gaps on mother to child transmission prevention strategies. Thus this study assess the level of knowledge of HIV positive mothers towards feeding options, their current feeding option and associated factors at the study area.

\section{Methods and Material}

\subsection{Study Area and Design}

The study was conducted at Ambo Town, West Shoa Zone, Oromia regional state, Ethiopia. Ambo town is found at $110 \mathrm{Km}$ to the West direction of Addis Ababa Capital city of Ethiopia. There are four public health facilities which provide PMTCT service in the town, namely Awaro Health Center, Ambo Health Center, Ambo General Hospital, and Ambo University Referral Hospital. During the study period of this work, there were a total of 180 mothers attending PMTCT in the town. The study was conducted from April, 10 - July 20/2019. Institution based cross-sectional study design was utilized in this study.

\subsection{Study Populations and Sample Size}

All mothers who have children aged 6-24 months attending PMTCT clinics at public health facilities of Ambo town were source population. All randomly selected mothers attending PMTCT clinics were included in this study. The following assumptions were considered while calculating the sample size. Ninety five percent confidence level $(\mathrm{CI}=95 \%)$, $90.40 \%$ proportion $(\mathrm{P})$ of exclusive breastfeeding under six months of age among HIV positive mothers [19], 10\% on response rate. Finally the sample size is calculated using single population formula.

$$
n=\frac{(Z \alpha / 2)^{2}(P)(1-p)}{d^{2}}=\frac{(1.96)^{2}(0.904)(1-0.904)}{0.05^{2}}=134
$$

Therefore a total of 134 mothers were studied.

\subsection{Sampling Technique and Data Collection}

First study subjects are allocated to each institution proportion to the patient load. Then systematic random sampling technique was applied using registration card as a frame to select the eligible study subjects. A structured questionnaire which included socio-demographic and health related factors were prepared based on objectives of the study after reviewing different literatures. Pre-test of the questionnaires were done on $5 \%$ of the study subjects at Guder health center (Other than study area) to check reliability, acceptability and time required for the interview and then corrections were made accordingly.

\subsection{Data Processing and Analysis}

Data was coded and entered to Epi-data version 3.1 and exported to SPSS version 21 for analyses. Frequency, mean and standard deviations from descriptive statistics and analytic statistics such as bivariate and multivariable logistic regression analysis were computed to determine the effect of various factors on the outcome variable. Variables having Pvalue less than or equal to 0.05 on bivariate logistic regression were the candidate for multivariable logistic regressions. Statistical significance was declared at $\mathrm{P}<0.05$. The strength of association between independent and dependent variables was assessed using the adjusted odds ratio with $95 \%$ confidence interval.

\section{Results}

A total of 106 HIV positive mothers, who have children 624 months, were participated in the study making a response rate of $80.5 \%$.

\subsection{Socio-demographic Characteristics of the Study Population}

The mean age of the respondents were 29.54, \pm 5.58 standard deviation in years which ranges from 19 to 42 years old. Out of total study participants about $75.5 \%, 65.1 \%$, and $62 \%$ were from urban residence, Oromo and Orthodox in religion respectively. Out of total respondents 23.6, 28.3\% and $48.1 \%$ were uneducated, attended primary school and attended secondary\& above respectively. Out of total respondents the mean family monthly income was 3659.4 Ethiopian birr (Table 1).

\subsection{Maternal Health Related Characteristics}

This study revealed that the primary sources of information regarding infant feeding practice obtained from health care providers $94(88.7 \%)$, followed by mass media 7 $(6.6 \%)$ and friends 5 (4.7\%). More than $80 \%$ of study subjects were on WHO stage one and about 99 (93.4\%) discloses their status to their partner. Regarding their ANC follow up $98(92.5 \%)$ of them had antenatal follow up, of whom $82(77.3 \%)$ attended ANC three and above and about $93(87.7 \%)$ delivered at health institution (Table 2). 
Table 1. Socio demographic characteristics of the study participants attending PMTCT clinic at Ambo town public health institutions, Ambo Ethiopia, 2019 $(n=106)$.

\begin{tabular}{|c|c|c|c|}
\hline Variables & Characteristics & Frequency (n) & Percent (\%) \\
\hline \multirow{3}{*}{$\begin{array}{l}\text { Age } \\
\text { Mean } \pm \mathrm{SD}=29.53 \pm 5.58\end{array}$} & $<25 \mathrm{yrs}$ & 28 & 26.4 \\
\hline & $25-30 \mathrm{yrs}$ & 34 & 32 \\
\hline & $>=30 \mathrm{yrs}$ & 44 & 42 \\
\hline \multirow{5}{*}{ Ethnicity } & Oromo & 72 & 68 \\
\hline & Amhara & 26 & 24.5 \\
\hline & Tigre & 2 & 1.8 \\
\hline & Others ${ }^{* 1}$ & 6 & 5.6 \\
\hline & Orthodox & 62 & 58.5 \\
\hline \multirow{3}{*}{ Religion } & Protestant & 23 & 21.7 \\
\hline & Muslim & 4 & 3.8 \\
\hline & Others $^{* 2}$ & 17 & 16 \\
\hline \multirow{2}{*}{ Duration of stay with partner } & $<5 \mathrm{yrs}$ & 24 & 22.6 \\
\hline & $>=5 \mathrm{yrs}$ & 82 & 77.4 \\
\hline \multirow{5}{*}{ Educational status of wife } & Illiterate & 25 & 23.6 \\
\hline & Read and write & 8 & 7.5 \\
\hline & 1-8 Grade & 22 & 20.8 \\
\hline & secondary & 37 & 34.9 \\
\hline & Diploma and above & 14 & 13.2 \\
\hline \multirow{5}{*}{ Occupational status of wife } & Farmer & 26 & 24.5 \\
\hline & Government employee & 22 & 20.8 \\
\hline & Merchant & 20 & 18.9 \\
\hline & Private work & 32 & 30.2 \\
\hline & Others $^{* 3}$ & 6 & 5.7 \\
\hline \multirow{3}{*}{ Family monthly income } & $<1500$ & 5 & 4.7 \\
\hline & $1501-3000$ & 40 & 37.7 \\
\hline & $>3001$ & 61 & 57.5 \\
\hline \multirow{2}{*}{ Residence } & Urban & 80 & 75.5 \\
\hline & Rural & 26 & 24.5 \\
\hline
\end{tabular}

Others ${ }^{* 1,2,3}$ indicates Gurage, Wakefata and daily laborer respectively.

Table 2. Health and health related characteristics of mothers attending PMTCT at Ambo town public health institution, Ambo, Ethiopia, 2019 ( $n=106)$.

\begin{tabular}{|c|c|c|c|}
\hline Variable & Categories & Frequency (n) & Percent (\%) \\
\hline \multirow{2}{*}{ Maternal breast condition } & Normal & 104 & 98.1 \\
\hline & Diseased & 2 & 1.9 \\
\hline \multirow{2}{*}{ Duration of time since diagnosis } & $<=2$ yrs & 54 & 51 \\
\hline & $>2 \mathrm{yrs}$ & 52 & 49 \\
\hline \multirow{2}{*}{ Did you start HAART } & Yes & 106 & 100 \\
\hline & No & 0 & 0 \\
\hline \multirow{2}{*}{ Did your partner start HAART } & Yes & 98 & 92.5 \\
\hline & No & 8 & 7.5 \\
\hline \multirow{3}{*}{ Initial CD4 count } & $<350$ & 5 & 4.7 \\
\hline & $350-500$ & 28 & 26.4 \\
\hline & $>=500$ & 73 & 68.8 \\
\hline \multirow{3}{*}{ WHO clinical stage } & 1 & 82 & 77.3 \\
\hline & 2 & 21 & 19.8 \\
\hline & $3 / 4$ & 3 & 2.8 \\
\hline \multirow{2}{*}{ Maternal PMTCT intervention } & Yes & 106 & 100 \\
\hline & No & 0 & 0 \\
\hline \multirow{2}{*}{ Type of maternal PMTCT regiment } & $\mathrm{TDF}+3 \mathrm{TC}+\mathrm{EVF}$ & 105 & 99.1 \\
\hline & $\mathrm{AZT}+3 \mathrm{TC}+\mathrm{NVP}$ & 1 & 0.9 \\
\hline \multirow{2}{*}{ Maternal ART adherence } & Good & 96 & 90.5 \\
\hline & poor & 10 & 9.5 \\
\hline \multirow{3}{*}{ Mid-Upper arm Circumference of mother } & $<22 \mathrm{~cm}$ & 35 & 33 \\
\hline & $22-24.5 \mathrm{~cm}$ & 64 & 60.3 \\
\hline & $25-30 \mathrm{~cm}$ & 7 & 6.6 \\
\hline \multirow{4}{*}{ Place of delivery } & Home & 13 & 12.3 \\
\hline & Government hospital & 54 & 50.9 \\
\hline & Governmental health centre & 39 & 36.8 \\
\hline & subtotal & 106 & 100 \\
\hline \multirow{4}{*}{ Birth attendants } & Health professionals & 89 & 84 \\
\hline & Health extension workers & 4 & 3.7 \\
\hline & TBA & 10 & 9.4 \\
\hline & Relatives & 3 & 2.8 \\
\hline
\end{tabular}




\begin{tabular}{llll}
\hline Variable & Categories & Frequency (n) & Percent (\%) \\
\hline \multirow{2}{*}{ Counseled on infant feeding Option } & Yes & 93 & 87.7 \\
& No & 13 & 12.3 \\
\hline
\end{tabular}

\subsection{Infant Feeding Practice}

This study determine that the proportion of HIV exposed feeding practice which showed that the majority $57(53.8 \%)$ were Exclusively Breast fed (EBF) whereas 19 (17.9\%) were practiced Exclusive Replacement Feeding (ERF) and the rest 30 (28.3\%) practiced Mixed Feeding (MF). Generally 76
(71.7\%) and $30(28.3 \%)$ mothers were practiced appropriate and in appropriate breast feeding practice. Study result identified that the main reason reported for Exclusive Breast Feeding due to advice by health workers $(89.7 \%$,) nutritional importance $(4.3 \%)$, easily availability of breast milk (4\%) and $3 \%$ wide community acceptability.

Table 3. Factors affecting HIVexposed infant feeding practice among mothers attending PMTCT clinic at Ambo town public health institution, Ambo, Ethiopia, $2019(n=106)$.

\begin{tabular}{|c|c|c|c|c|c|c|}
\hline \multirow{2}{*}{ Variables } & & \multicolumn{2}{|c|}{ Feeding practice } & \multirow{2}{*}{ COR } & \multirow{2}{*}{$\begin{array}{l}\text { AOR } \\
95 \% C I\end{array}$} & \multirow{2}{*}{ P -value } \\
\hline & & inappropriate & appropriate & & & \\
\hline \multirow{4}{*}{$\begin{array}{l}\text { Educational status of } \\
\text { the wife }\end{array}$} & uneducated & 17 & 8 & 0.078 & $0.81(0.010-0629)$ & 0.004 \\
\hline & Read \& write & 4 & 4 & 0.167 & $0.160(0.019-1.345)$ & 0.085 \\
\hline & Primary and Secondary & 3 & 19 & 1.056 & $1.063(0.149-7.590)$ & 0.956 \\
\hline & Diploma \&above & 2 & 12 & 1.375 & 1 & 0.732 \\
\hline \multirow{2}{*}{ Residence } & urban & 16 & 64 & 4.667 & $0.481(0.097-2.394)$ & 0.001 \\
\hline & rural & 14 & 12 & 0.857 & 1 & \\
\hline Monthly income & Below mean & 20 & 36 & 0.810 & 1 & \\
\hline \multirow{2}{*}{ WHO clinical stage } & Stage 1 & 19 & 66 & 3.821 & $2.295(0.604-8.720)$ & 0.008 \\
\hline & Stage 2 \&above & 11 & 10 & 0.909 & 1 & \\
\hline
\end{tabular}

\subsection{Factors Associated with HIV Exposed Infant Feeding Practice}

Multivariate analysis of this study revealed that educational status, place of residence and WHO clinical stage of the mother were found to be significantly associated with feeding practice. According to this study finding educated mothers were less likely to practice appropriate breast feeding as compared to educated mothers (those who have Diploma and above $) \quad \mathrm{AOR}=0.81 \quad(95 \% \mathrm{CI}, 0.010-0629)$. Additionally residence were found to be significantly associated with feeding practice $\mathrm{AOR}=0.481(95 \%$ CI $0.097-2.394)$. Finally WHO clinical stage was also significantly associated with feeding practice. Those mothers who were in WHO clinical stage I was 2.3 times more likely to practice appropriate breast feeding as compared to those who were in WHO clinical stage II and above, AOR=2.295 (95\% CI 0.604-8.720).

\section{Discussion}

The final analysis of this study revealed that $53.8 \%$ of HIV positive mothers had practiced exclusive breastfeeding. This finding is lower than other pocket studies conducted at Nigeria (91.7\%), Tigray Ethiopia (90.4\%) and Gondar Ethiopia $(83.8 \%)$ [ $7,19,20,21]$. This may be due to the socio demographic characteristics difference of the study subjects at different study area. On the other hand $17.9 \%$ of the subjects have practiced exclusive replacement feeding for the first six month. This proportion is higher than study conducted at Kenya $(8.2 \%)$, Nigeria $(0.7 \%)$, Tigray Ethiopia (3.7\%), Gondar Ethiopia (5.7\%), but lower than study conducted at South Africa (50\%) [2, 5, 19, 20, 21]. This may be due to the mothers were government employee (20.8\%), private worker $(30.2 \%)$ by occupation and educational status of the study subject which can affect exclusive breast feeding.

Furthermore, this study assesses mixed feeding practice of the study participants. Accordingly $28.3 \%$ of HIV positive mothers practiced mixed feeding option. This is lower than report from Kenya $(29.3 \%)$ but higher than South Africa $(12.4 \%)$, Nigeria (7.6\%), Tigray $(5.9 \%)$ and Gondar $(10.5 \%)$ $[2,6,20,21]$. This may be due to absence of advice regarding feeding option as $12.3 \%$ of this study participant didn't receive advice; in addition there was also $12.3 \%$ home delivery in this study which in turn affects choice regarding feeding options.

Regarding duration of breast feeding, majorities (45\%), of infants had discontinued breast feeding at six months. This in contrast to WHO recommendation which recommends mothers living with HIV should breastfeed for at least 12 months and may continue up to 24 months or beyond while they are receiving ART [9]. This might be due to lack of advice regarding duration of breast feeding, occupational status and educational status of the study subjects.

As to factors associated with feeding practice, educational status was significantly associated with feeding practice among HIV positive mothers at the study area. It was found that educated mothers were less likely to practice appropriate feeding option as compared to educated mothers (those who have Diploma and above) AOR= 0.81 (95\% CI, 0.010-0629). This may be due to the fact that as education is the key determinants of health and it was also included in UNICEF conceptual framework of malnutrition as underlying cause of malnutrition. Additionally residence were found to be significantly associated with feeding practice $\mathrm{AOR}=0.481$ (95\% CI 0.097-2.394). Those mothers who were urban 
residents were $52 \%$ less likely to practice appropriate feeding options as compared to rural residents. This may be due to easy accessibility of foods like infant formula and occupational status of mothers in urban as government employee. Finally WHO clinical stage was also significantly associated with feeding practice. Those mothers who were in WHO clinical stage-I was 2.3 times more likely to practice appropriate breast feeding as compared to those who were in WHO clinical stage II and above, $\mathrm{AOR}=2.295(95 \% \mathrm{CI}$ 0.604-8.720). This may be due to fear of HIV transmission as viral load increase, WHO stage also increase and then risk of transmission to infant also increases. Thus it is better to give more emphases to all infant feeding options like Wet nursing, Heat treated breast feeding and exclusive replacement feeding where Exclusive breast feeding is not practical.

\section{Limitation of Study}

Cause and effect relation was not assured because of crosssection study design.

\section{Conclusion}

This study revealed that, majorities $(71.7 \%)$ of the study participants have practiced appropriate feeding option (Either exclusive replacement feeding or exclusive breast feeding). Whereas $28.3 \%$ of the study subjects practice inappropriate feeding option (mixed feeding). Factors like Maternal educational status, residence and WHO clinical stage were significantly associated with feeding practice.

\section{Declarations}

\section{Ethical Consideration}

Ethical clearance was received from Ethical Review Committee of College of Medicine and Health sciences of Ambo University. Verbal consent was obtained from the study subjects after they had been informed about the objectives and procedures of the study.

\section{Funding Statement}

There was no funding source for this study.

\section{Authors' Contributions}

KT conceptualized the paper, searched literature, trained field researchers for data collection and wrote the results and discussion sections. In addition $\mathrm{KT}$ also has critically reviewed the result and prepared the manuscript for publication.

\section{Competing Interests}

The author declares no competing interests.

\section{Acronyms and Abbreviations}

\author{
ART: Anti Retro viral Therapy, \\ EBF: Exclusive breast feeding, \\ ERF: Exclusive replacement feeding, \\ HAART: Highly active antiretroviral therapy, \\ HIV: Human Immunodeficiency Virus, MF: mixed \\ feeding, \\ MOH: Ministry of health, \\ PLWHA: People living with HIV/AIDS, \\ SPSS: Statistical Package for Social Sciences.
}

\section{Acknowledgements}

It gives me a great respect to thank all study participants for their cooperation in providing the necessary information. My gratitude is great to research assistants who participated in data collection and supervision in this study. Finally, great thank goes to Ambo University and Public health facilities in Ambo Town for logistic support during data collection.

\section{References}

[1] Wang L. Overview of the HIV/AIDS epidemic, scientific research and government responses in China Aids. 2007 Dec 1;21: S3-7.

[2] Newell, M. L., 2004. HIV transmission through breastfeeding: a review of available evidence.

[3] UNAIDS, W., 2017. Fact sheet: world AIDS day 2017. Global HIV statistics.

[4] Berhe, A., Tesfahun, H., Joshi, S. and Bayray, A., Assessment of Infant feeding experience of HIV Positive mothers utilizing PMTCT services: The case of TikurAnbassa Hospital, Addis Ababa, Ethiopia. Int J Pharm Sci Res 2013; 4 (5); 1000, 1018.

[5] Haile, D., Belachew, T., Berhanu, G., Setegn, T. and Biadgilign, S., 2015. Complementary feeding practices and associated factors among HIV positive mothers in Southern Ethiopia. Journal of Health, Population and Nutrition, 34 (1), p. 5.

[6] Legesse, H, Degefie, T., Hiluf, M. Sime, K., Tesfaye, C., Abebe, H., Kebede, H, Pearson, L., Kassaye, A. and Taylor, M., 2014. National scale-up of integrated community case management in rural Ethiopia: implementation and early lessons learned. Ethiop Med J, 52 (Suppl 3), pp. 1526.

[7] WHO, U., 2016. Guideline: updates on HIV and infant feeding: the duration of breastfeeding, and support from health services to improve feeding practices among mothers living with HIV. Geneva: World Health Organization.

[8] World Health Organization, 2010. Guidelines on HIV and Infant Feeding 2010: Principles and Recommendations for Infant Feeding in the Context of HIV and a Summary of Evidence. Geneva: World Health Organization.

[9] UNICEF. Division of Communication, 2009. Tracking progress on child and maternal nutrition: a survival and development priority. Unicef. 
[10] Joint United Nations Programme on HIV/AIDS., UNICEF. and World Health Organization, 2008. Children and AIDS: Third Stocktaking Report, 2008. UNICEF.

[11] Fletcher, F. E., Ndebele, P. and Kelley, M. C., 2008. Infant feeding and HIV in Sub-Saharan Africa: what lies beneath the dilemma?. Theoretical medicine and bioethics, 29 (5), p. 307.

[12] Demographic, E. (2016). "Health Survey Central Statistical Agency." Addis Ababa, Ethiopia.

[13] Fadnes, L. T., Engebretsen, I. M. S., Moland, K. M., Nankunda, J., Tumwine, J. K. and Tylleskär, T., 2010. Infant feeding counselling in Uganda in a changing environment with focus on the general population and HIV-positive mothers-a mixed method approach. BMC health services research, 10 (1), p. 260.

[14] Ndubuka, J., Ndubuka, N., Li, Y., Marshall, C. M. and Ehiri, J., 2013. Knowledge, attitudes and practices regarding infant feeding among HIV-infected pregnant women in Gaborone, Botswana: a cross-sectional survey. BMJ open, 3 (11), p. e003749.

[15] Bekere, A., Garoma, W. and Beyene, F., 2014. Exclusive Breastfeeding Knowledge of HIV Positive mothers and Associated Factors in Selected Health Institution of West Oromia, Ethiopia. Universal Journal of Food and Nutrition Science, 2 (3), pp. 37-44.

[16] FHAPCO, F., 2007. Guideline for prevention of mother to child transmission of HIV in Ethiopia: Federal HIV. AIDS Prevention and Control office, Federal Ministry of Health.

[17] Fanta, W. and Worku, A., 2012. Determinants for refusal of HIV testing among women attending for antenatal care in Gambella Region, Ethiopia. Reproductive health, 9 (1), p. 8.

[18] Kalipeni, E., Iwelunmor, J., Grigsby-Toussaint, D. S. and Moise, I. K. eds., 2018. Public Health, Disease and Development in Africa. Routledge.

[19] Alemayehu, T., Haidar, J. and Habte, D., 2009. Determinants of exclusive breastfeeding practices in Ethiopia. Ethiopian Journal of Health Development, 23 (1).

[20] Maru, Y. and Haidar, J., 2009. Infant feeding practice of HIV positive mothers and its determinants in selected health institutions of Addis Ababa, Ethiopia. Ethiopian Journal of Health Development, 23 (2).

[21] Ladzani, R., Peltzer, K., Mlambo, M. G. and Phaweni, K., 2011. Infant-feeding practices and associated factors of HIVpositive mothers at GertSibande, South Africa. ActaPaediatrica, 100 (4), pp. 538-542.

[22] Saka, F. J., 2012. Factors influencing exclusive breastfeeding among HIV positive mothers at Ilala Municipality Dar es Salaam (Doctoral dissertation, Muhimbili University of Health and Allied Sciences).

[23] Maclaine, A., 2006. Infant Feeding Practices in Binga and Nyaminyami, Zimbabwe, in relation to HIV. 